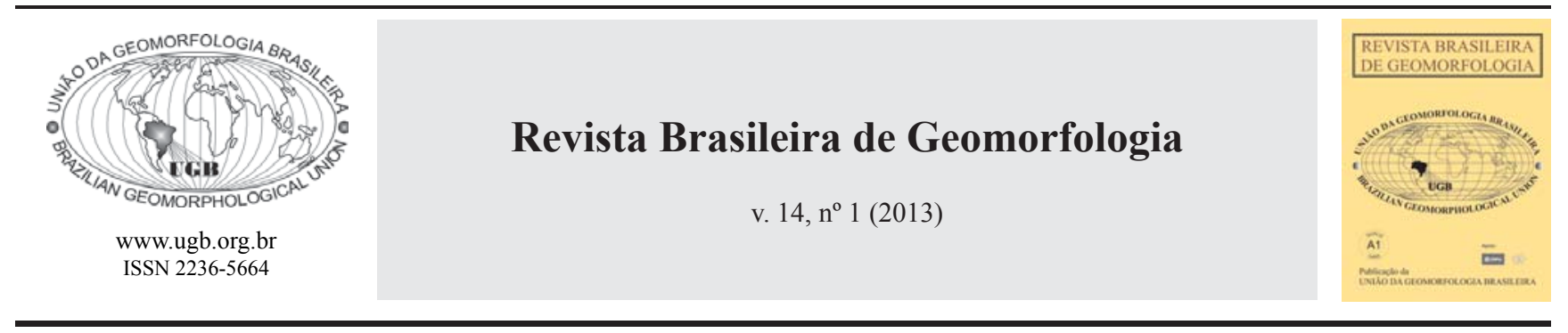

\title{
COMPARTIMENTAÇÃO DE UNIDADES GEOMORFOLÓGICAS DO MUNICÍPIO DE AGUDO/RS
}

\section{GEOMORPHOLOGICAL UNITS SUBDIVISION OF THE COUNTY OF AGUDO/RS}

\author{
Gerson Jonas Schirmer \\ Rua Muniz Ferraz, $n^{\circ}$ 97, Bairro Centro, Agudo/RS - CEP 96540-000. \\ E-mail: geogersonjs@gmail.com \\ Luís Eduardo de Souza Robaina \\ Departamento de Geociências - CCNE - UFSM - Av. Roraima, 1000, Prédio 17 \\ Cidade Universitária - Camobi - Santa Maria/RS - CEP 97105-900. \\ E-mail:lesrobaina@yahoo.com.br
}

\section{Informações sobre o Artigo}

Data de Recebimento:

$03 / 11 / 2011$

Data de Aprovação:

$14 / 06 / 2013$

\section{Palavras-chave:}

Mapeamento;

geomorfológico; paisagem.

\section{Keywords:}

Mapping; geomorphologic; landscape.

\section{Resumo}

Este artigo apresenta um mapeamento geomorfológico do município de Agudo-RS, onde as unidades geomorfológicas representam a integração dos elementos físicos da área de estudo, frente aos processos envolvidos na organização da paisagem local. A metodologia é fundamentada nas contribuições da ciência geográfica, utilizando como ferramenta SIGs (Sistemas de Informação Geográfica). Através de uma representação de síntese, foram definidos cinco unidades geomorfológicas, Rampas de Colúvio-Alúvio do Rio Jacuí, Rampas de Colúvio-Alúvio de Arroios, Colinas Alúvio-Coluvionar, Colinas Vulcânicas do Planalto Serra Geral e Associação de Morros e Morrotes do Rebordo do Planalto, que caracterizam a paisagem do município de Agudo.

\begin{abstract}
This paper presents a geomorphological mapping of the municipality of Agudo-RS, where geomorphologic units represent the integration of the physical elements of the study area, compared to the processes involved in the organization of the local landscape. The methodology is based on the contributions of geographical science, as a tool using GIS (Geographical Information Systems). Through a representative synthesis, were defined five geomorphological units, Ramps of Collúvium-Aluvio River Jacuí, Ramps Colluvium-Alúvio of Streams, Hills Alúvio-colluvial, Hills Volcanic Plateau Serra Geral, Association Morrotes the Border Hills and Plateau, that characterize the landscape of the county of Agudo.
\end{abstract}




\section{Introdução}

Na Geomorfologia, a cartografia é utilizada como meio de representação gráfica e espacial. Permite representar a gênese das formas do relevo e suas relações com a estrutura e os processos. A cartografia geomorfológica é um instrumento de análise e de síntese da pesquisa geomorfológica e, conforme ROSS (1990), as formas de relevo e os processos geomorfológicos têm grande importância, tanto pelo fato de constituírem o local onde se desenvolvem as atividades humanas, como por responderem muitas vezes de forma agressiva as alterações provocadas pela ação antrópica.

As características geomorfológicas constituem o produto integrador das formas e dos processos naturais e antrópicos que atuaram, e que ainda atuam sobre os componentes do meio físico. Dessa forma, de acordo com Penteado (1985), a compartimentação geomorfológica engloba as características morfométricas e morfológicas e os processos morfodinâmicos e morfogenéticos do relevo. Para chegar a esta caracterização do relevo, se faz necessário estabelecer relações entre os vários elementos do meio físico que vão compor a análise geomorfológica.

De acordo com essa ideia, o presente trabalho apresenta uma proposta de compartimentação geomorfológica do município de Agudo, a partir de informações em escala 1:50.000. Trabalhos norteadores nessa pesquisa são os realizados por De Nardin (2009), Schirmer (2010), Trentin (2011) e Menezes (2012). Estes trabalhos realizam mapeamentos geomorfológicos a partir da integração dos elementos naturais que compõem a paisagem.

O trabalho objetiva apresentar uma compartimentação das unidades geomorfológicas no município de Agudo localizado na região Centro Ocidental do Estado do Rio Grande do Sul, inserido na Microrregião de Restinga Seca (Figura 1). A altitude da sede de Agudo é de 83 metros, sendo que a altitude máxima chega aos 617 metros na região norte do município. A área total do município é de $536,12 \mathrm{~km}^{2}$, distanciando-se $250 \mathrm{~km}$ de Porto Alegre.

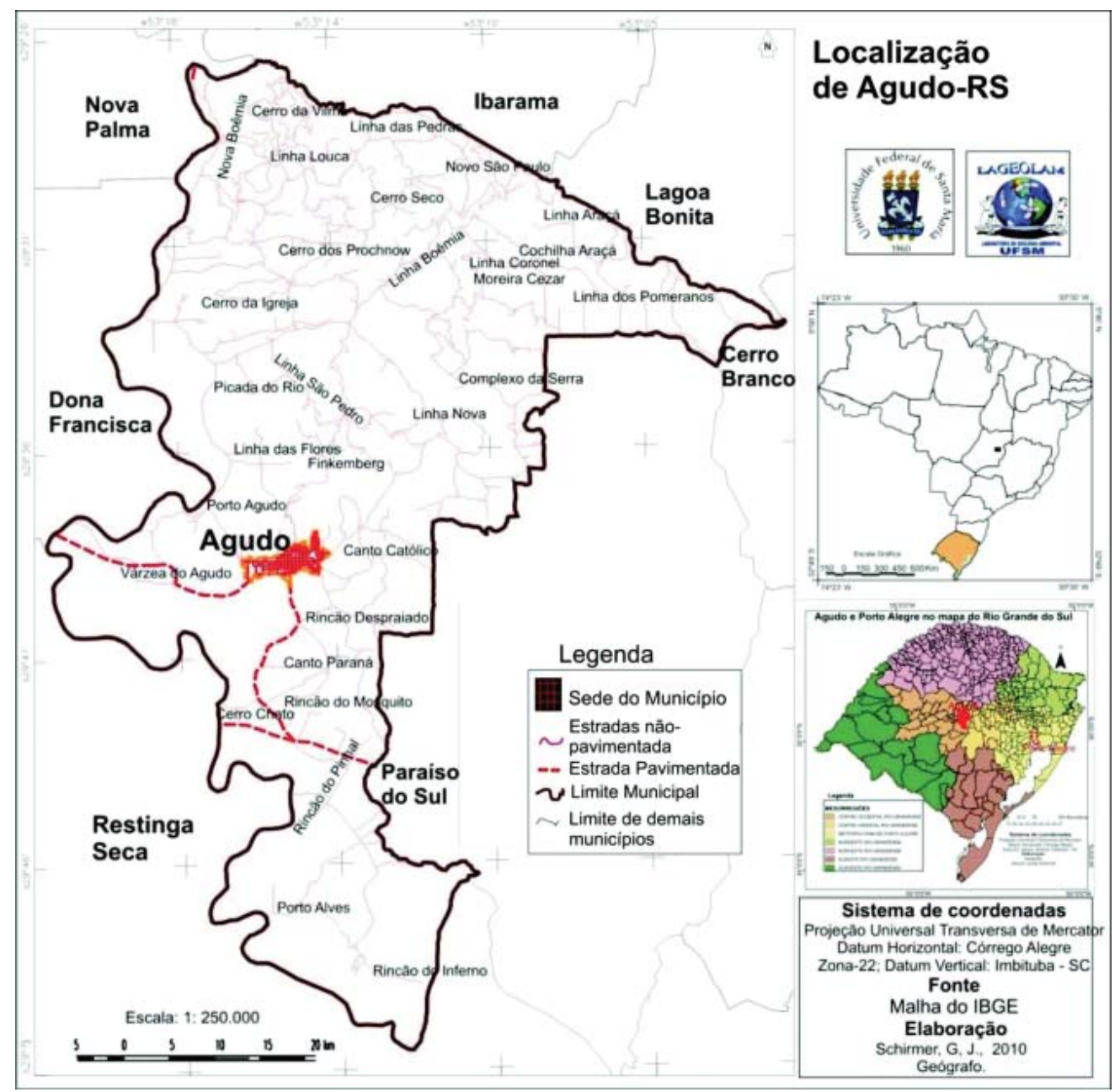

Figura 1 - Localização do município de Agudo. 


\section{Materias e Método}

O trabalho desenvolveu-se, basicamente, através de 3 etapas. A primeira etapa desenvolveu-se a partir de cartas topográficas elaboradas pela Diretoria de Serviços Geográfico (DSG/IBGE, 1977) do Ministério do Exército, na escala 1:50.000, definidas pela seguinte nomenclatura: Agudo (SH.22.V-C-V/2); Jacuí (SH.22.V-C-V-4); Nova Palma (SH.22-V-C-II-3); Faxinal do Soturno (SH.22-V-C-V-I); Sobradinho (SH.22-V-C-II-4); Restinga Seca (SH.22-V-C$\mathrm{V}-3$ ), onde foram obtidos dados morfométricos a partir das curvas de nível e da hidrografia.

A partir das formas de relevo e rede de drenagem obtiveram-se os primeiros mapas interpretativos de unidades de relevo, obtidos através da sobreposição dos mapas de declividade, hipsometria, da rede de drenagem, das curvas de nível no software ArcGis 9.3 e elaboração de perfis topográficos.

O mapa de declividade foi realizado a partir das seguintes classes estabelecidas pelo IPT (Instituto de Pesquisas Tecnológicas de São Paulo), como $<5 \%$; 5-15\%, onde: $<5 \%$ - Áreas de baixa declividade e onde se registram processos deposicionais; A partir desta inclinação o processo erosivo começa a ser significativo; 5 - 15\% - Faixa que define o limite máximo para o emprego da mecanização na agricultura; e, áreas propícias à ocorrência de processos de movimentos de massa. Para melhor caracterizar a área foram acrescentadas ainda mais três classes sugeridas por De Biase e Hertz (1989): 15-30\% - é definido por legislação federal - Lei 6766/79, também chamada de Lei Lemann, que vai definir o limite máximo para urbanização sem restrições, a partir do qual toda e qualquer forma de parcelamento far-se-á através de exigências específicas; $30-47 \%\left(25^{\circ}\right)$, definido pelo código florestal como limite máximo de corte raso, a partir do qual a exploração só será permitida se sustentada por cobertura de florestas - Lei 4771/65 15/09/65, revogada pela Lei 12.651/12; $>47 \%$ o artigo do código florestal prevê que acima de $25^{\circ}$ de inclinação não é permitida a derrubada de florestas, só sendo tolerada a extração de toras, quando em regime de utilização racional, que vise a rendimentos permanentes.Essas classes foram criadas por serem as que melhor dividem os processos de dinâmica superficial e de usos existentes.

As informações e análises sobre litologias, solos e feições superficiais foram baseadas nos dados coletados em campo com GPS (Sistema de Posicionamento Global). As imagens de satélite Ikonos e mapas gerados a partir de dados do Modelo Digital de Elevação, obtido com as curvas de nível com equidistância de 20 metros (declividade e hipsometria), integraram o material cartográfico utilizado para a realização dos levantamentos de informações atualizadas. A imagem Ikonos serviu para identificar algumas informações obtidas em campo, como a caracterização dos tipos de uso, forma da vertente e a existência de feições decorrentes dos processos de dinâmicas superficiais.
A etapa final a elaboração da compartimentação geomorfológica do município de Agudo, com base cartográfica na escala de trabalho 1:50.000, construído no software ArcGis9.3, dos mapas de unidades de declividade, hipsométrico, rede de drenagem, solos e mapa litológico, sendo que estes dois últimos foram obtidos a partir da coleta de amostras em campo com o GPS e com o mapa de declividade, com escala final 1:50.000. Com as imagens Ikonos e informações e fotografias coletadas em campo, foram delimitadas e analisadas as unidades Geomorfológicas em um mapa síntese das informações obtidas sobre o meio físico.

\section{Área de Estudo}

O município faz parte da bacia hidrográfica do rio Jacuí, sendo composto por 12 subbacias hidrográficas. O sentido principal das drenagens é de NE-SW, desaguando junto ao Rio Jacuí e formando arranjo espacial retangular-dendrítico associado às linhas de fraturas existentes nas rochas vulcânicas do substrato rochoso e as grandes lineações existentes do Brasiliano.

O município de Agudo apresenta como menor cota altimétrica o nível de 20 metros e a maior cota é de $617 \mathrm{me}-$ tros, resultando em uma amplitude altimétrica de 597 metros (Figura 2).

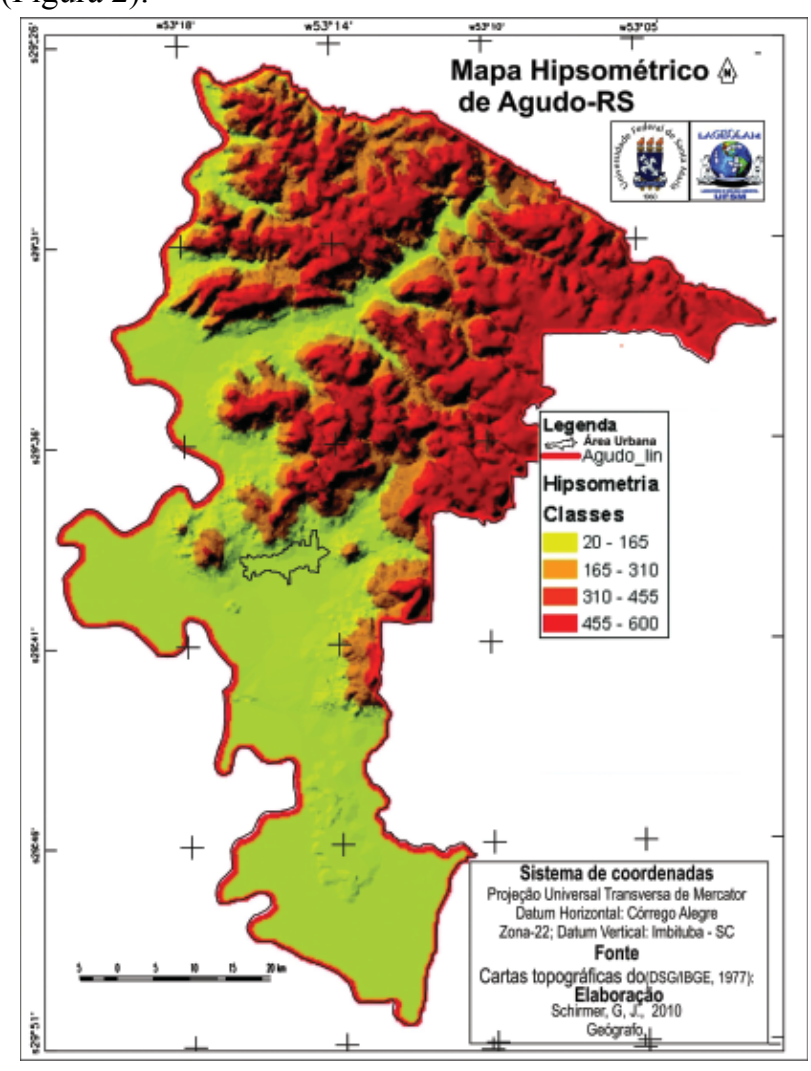

Figura 2 - Mapa Hipsométrico. 
As áreas de menores altitudes ocorrem às margens do rio Jacuí adentrando, principalmente, as porções planas dos arroios Grande e Corupá. Essa área sofre influência deposicional de sedimentos transportados pelo rio Jacuí e dos arroios citados, formando uma planície de inundação.

$\mathrm{Na}$ região norte e nordeste são onde encontram-se as porções mais elevadas do relevo. Essa área apresenta topografia ondulada a suavemente ondulada.

O intervalo de declividade predominante em Agudo é o menor de $5 \%$, e distribuem-se em todas as altitudes, sendo que nas altitudes mais elevadas elas pertencem as primeiras porções do planalto (Figura 3). As áreas de baixa declividade também ocorrem associadas às vertentes amplas e suaves das colinas da Depressão Periférica conforme IBGE (2007). Este intervalo corresponde a áreas caracterizadas por um relevo plano. Em baixas altitudes, junto à rede de drenagem, podem ocorrer processos de inundação e de acumulação de sedimentos, onde no município é realizado o cultivo do arroz.

As declividades acima de $47 \%$ marcam área de importante ruptura do relevo, associadas ao contato das terras altas do Planalto com as terras baixas da Depressão formando o Rebordo do Planalto. As áreas que apresentam declividade enquadrada nesta área são consideradas de Áreas de preservação permanentes pelo código florestal, Lei 12.651/12 e são considerada as áreas com declividade superior a 45 graus, as entre $47 \%$ e $100 \%$ são de uso restrito, que não permite corte raso.

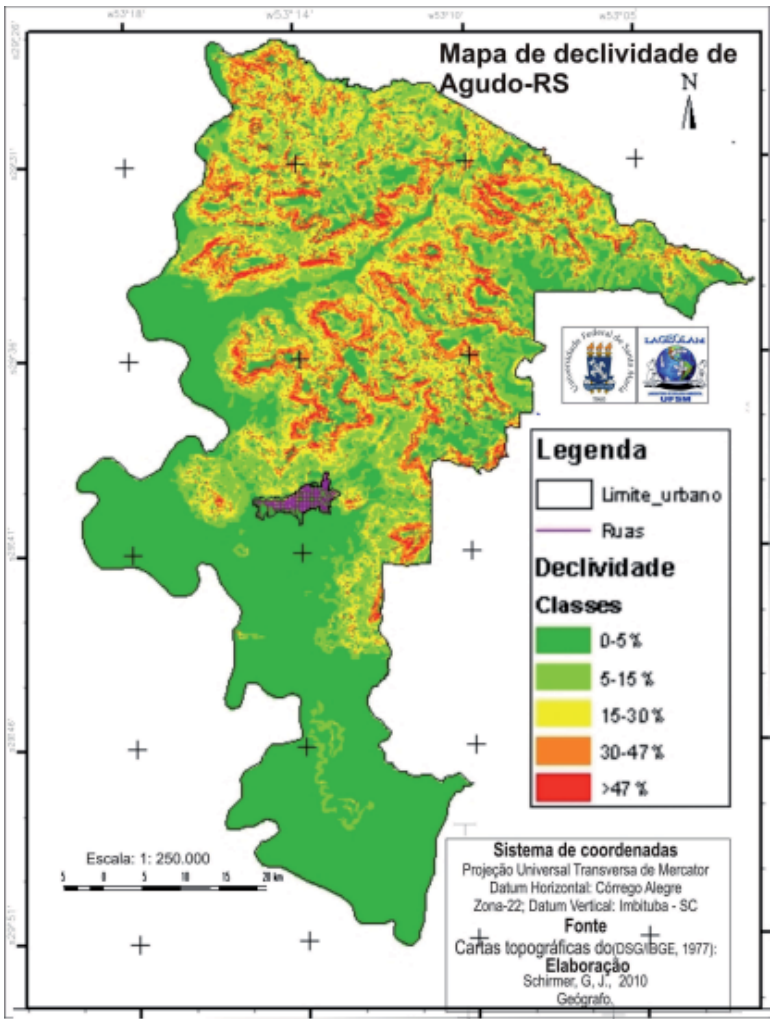

Figura 3 - Mapa de Declividade.
O município de Agudo está inserido no limite meridional na Bacia Sedimentar do Paraná que representa uma extensa bacia constituída por rochas sedimentares e vulcânicas que recobre 1.500.000 $\mathrm{Km}^{2}$ do território Sul Americano. No estado do Rio Grande do Sul, esta bacia recobre as porções norte e oeste do estado. A Bacia Sedimentar do Paraná tem sua formação entre a Era Paleozóica e o final da Era Mesozóica, totalizando 450 milhões de anos (Holz e De Roz, 2002).

As litologias da Bacia Sedimentar do Paraná que aparecem no município de Agudo estão correlacionadas a três ambientes de formação distintos, que são resultado da evolução das paisagens ao longo do tempo geológico: um sistema fluvial, um sistema desértico e rochas vulcânicas (Figura 4).

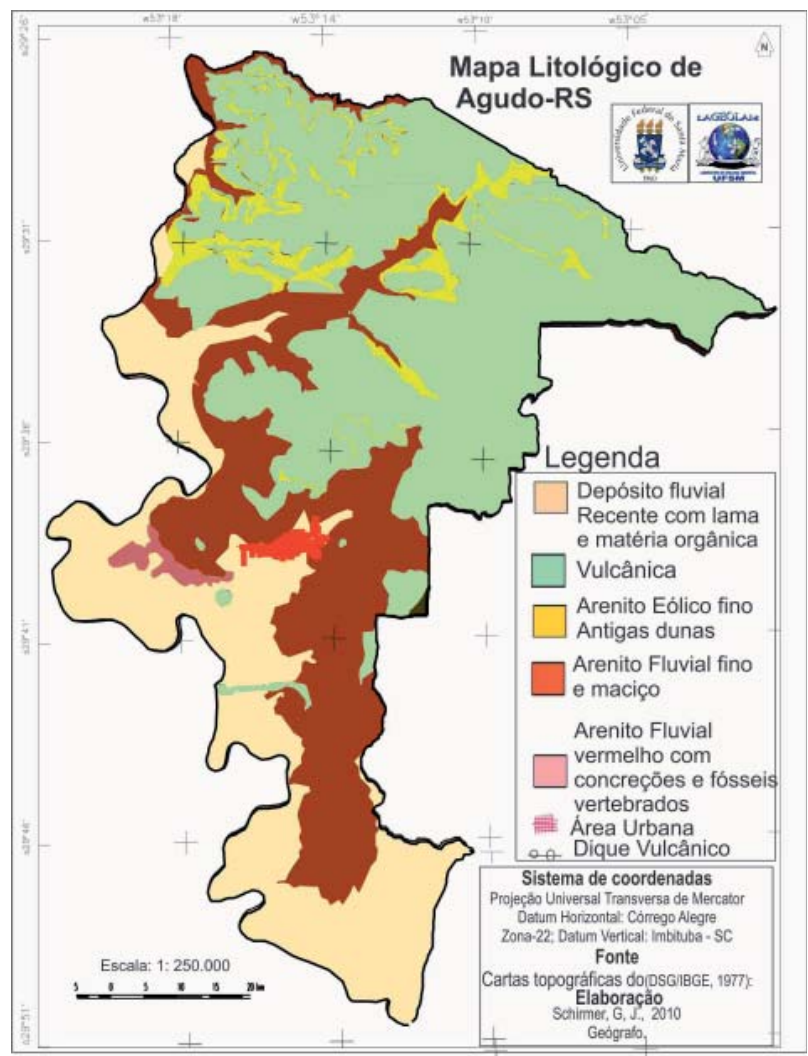

Figura 4 - Mapa com as litologias no municipio de Agudo.

As rochas mais antigas estão representadas por Lutitos vermelhos maciços e laminados com concreções e vertebrados fósseis, que sofreram processo de carbonatação. Ocorrem intercalações lenticulares de camadas argilosas esbranquiçadas e endurecidas, com espessura de até $30 \mathrm{~cm}$, com laminação horizontal relacionado a ambientes lacustre temporários de canais efêmeros. Além disso, estão presentes conglomerados 
intraformacionais lenticulares com até $50 \mathrm{~cm}$ de espessura. Conforme mapeamento de WILDNER, et al (2006), podem ser classificados como da Formação Santa Maria de idade Triássico. Estratigraficamente acima destas litologias ocorre um substrato rochoso caracterizado por arenitos finos, cor branca, lenticulares, maciços e com laminação horizontal e cruzada acanalada de médio e grande portes. Além disso, apresenta conglomerados intraformacionais e lutitos vermelhos laminado. Essa litologia encontra-se na área de base do Rebordo do Planalto, em altitudes acima de 80 metros, podendo atingir cotas altimétricas de 280 metros. Observando o mapeamento realizado pelo serviço Geológico do Brasil (2006) determina-se que fazem parte da Formação Caturritas de idade Triássico Superior

Seguem, com forte associação com as rochas vulcânicas sobrepostas, arenitos bem classificados com espessuras variadas de pouco mais de $1 \mathrm{~m}$ até $40 \mathrm{~m}$, interpretados como da Formação Botucatú, que caracteriza depósitos eólicos.

As rochas vulcânicas, da Formação Serra Geral de idade final do Jurássico e início do Cretáceo, apresentam composição básica e ácida, originadas a partir dos derrames provenientes do vulcanismo fissural, ocorrido na bacia do Paraná durante a Era Mesozóica.

Estas rochas ocorrem arranjadas conforme um padrão decrescente de idades em direção ao topo. Isso reflete um comportamento de empilhamento de lavas, em diferentes derrames, determinados pela observação da textura e estrutura das rochas. A sequência de derrames é identificada na forma de patamares nas encostas.

Os depósitos recentes marcam acumulação das drenagens da região formando pequenas faixas de deposição próximas aos cursos da água, predominando a fração areia quartzosa com grânulos e seixos de rochas vulcânicas. Pode-se observar, também, depósito de antigo canal fluvial com seixos vulcânicos, formando terraços do Jacuí. Nas porções onde a declividade é muito baixa e tem-se o cultivo do arroz, pode-se encontrar sedimentos lamosos de cor preta e cinza escuro, proveniente da acumulação de matéria orgânica.

O croqui com perfil geológico, figura 5, apresenta as litologias encontradas no município. As porções mais elevadas e inclinadas e elevadas são compostas por rochas vulcânicas e a presença de arenito eólico entre as rochas vulcânicas e sob elas, sendo que quando está na forma de intertraps está separando dois derrames. Os depósitos de colúvio localizamse nas porções de base das encostas sobre arenitos eólicos ou quando este não está presente está sobre arenito fluvial. O material composto é proveniente de rocha intemperizada, formando uma mistura de blocos seixos, matéria orgânica e solo. A base da sequência é composta por uma associação de arenitos e lamitos de ambiente fluvial com ocorrência de fósseis.

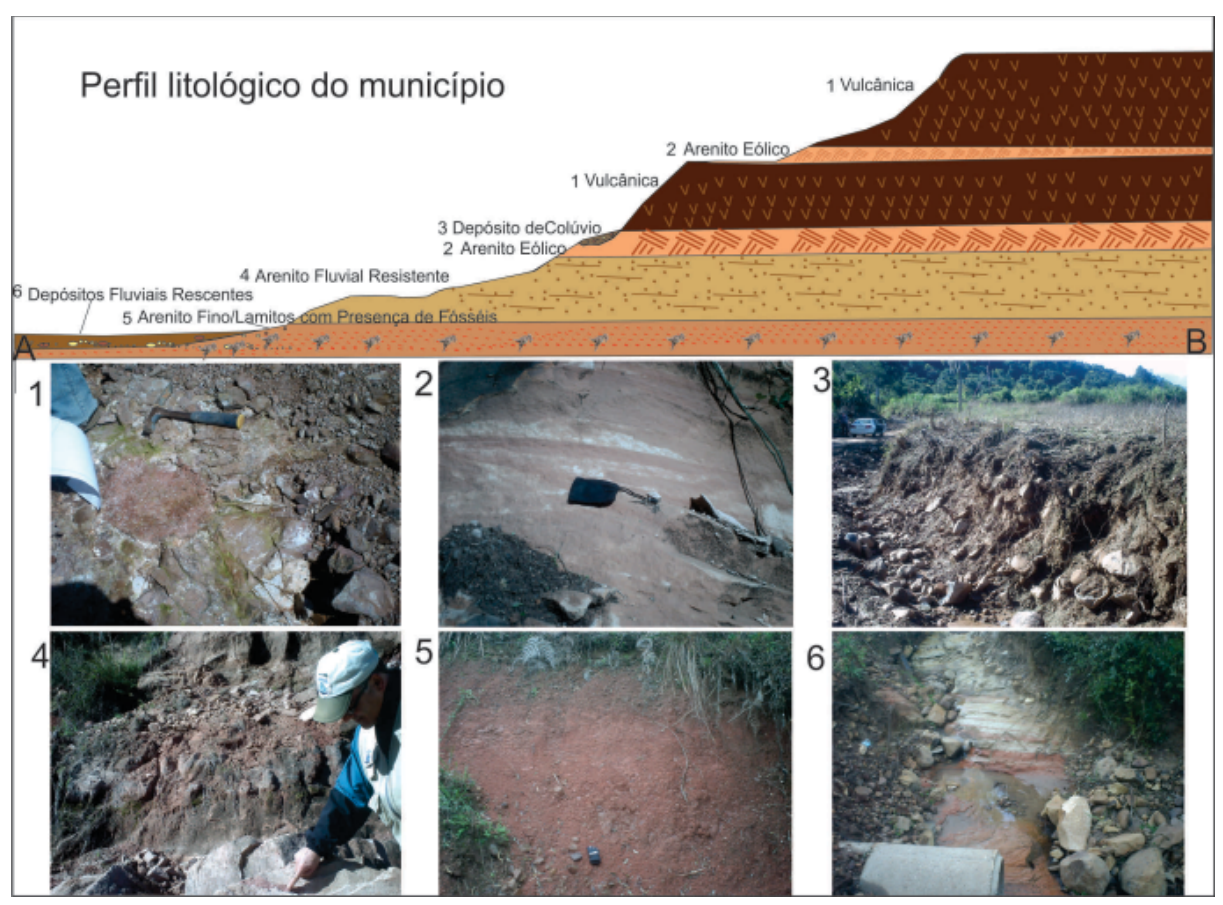

Figura 5 - Perfil Litológico noroeste-sudeste da região noroeste do município. 


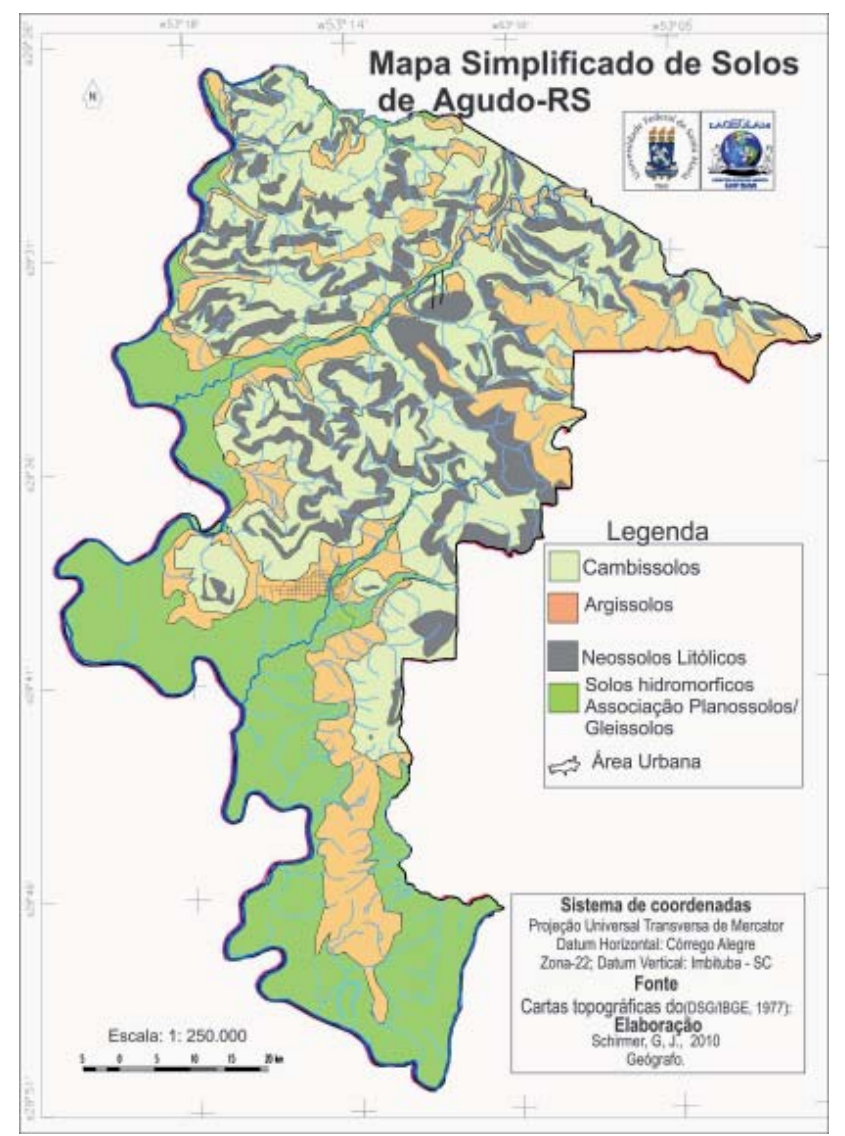

As características dos solos foram identificadas com trabalhos de campo e classificados de acordo com as classes adotadas pela Sociedade Brasileira de Ciência do Solo. Com relação aos solos, de modo geral, quando bem desenvolvidos são do tipo Argissolos, com textura argilo-arenosos, com significativo material ligante, desenvolvidos sobre substrato de arenitos, mas com influência das rochas vulcânicas.

Os solos rasos estão associados ao relevo inclinado ou a rochas vulcânicas, mais resistentes na região, se caracterizam por Cambissolos e Neossolos Litólicos. Nas áreas junto à várzea do Jacuí ocorrem os hidromórficos identificados como Planossolos e Gleissolos (Figura 6).

\section{Compartimentação e Mapeamento Geomorfológico}

O município de Agudo está incluído nas unidades geomorfológicas do Planalto da Serra Geral, da encosta da Serra Geral e as porções de menor altitude pertencem a Depressão Periférica do Jacuí (RADAM BRASIL - IBGE- escala 1: 1.000.000) (2003).

No perfil apresentado na figura 7 , de sudoeste à nordeste do município, pode-se observar a diversidades do substrato, relevo e uso na área de estudo, que tendem a seguir as restrições impostas pelo meio físico, principalmente com relação ao relevo.

Figura 6 - Mapeamento simplificado de solos do Municipio de Agudo.

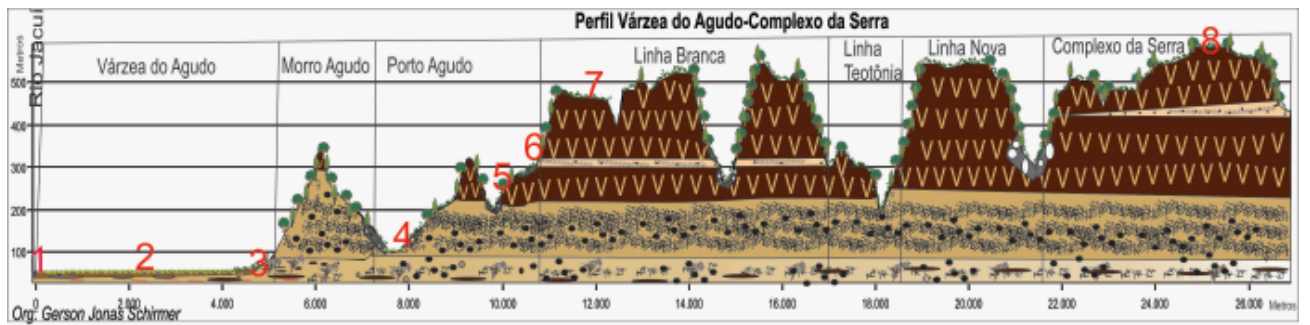

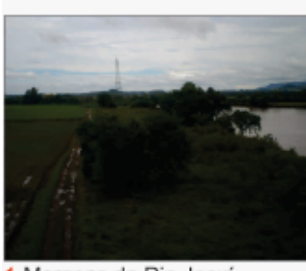

1-Margens do Rio Jacuí

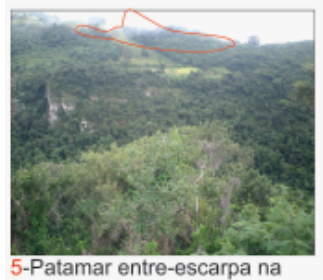

rocha vulcånica

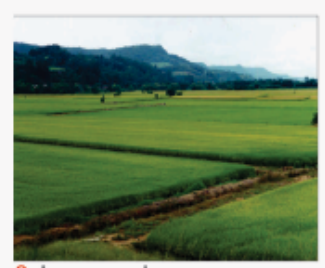

2- Lavouras de arroz na Planicie

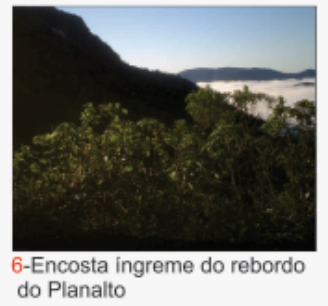

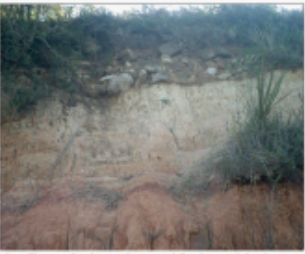

3- Depósito de colúvio-alúvio sobre arenito Friável

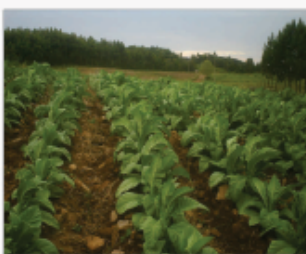

7-Colinas de rochas vulcânicas e solos do tipo associação e solos do tipo associaça

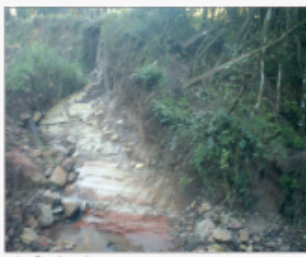

4-Coluvio em contato com arenito Fluvial

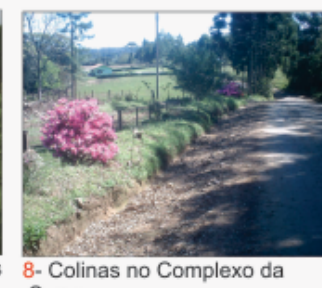

Serra

Figura 7 - Perfil geomorfológico de direção sudoeste-nordeste entre as regiões Várzea do Agudo e Complexo da Serra . 


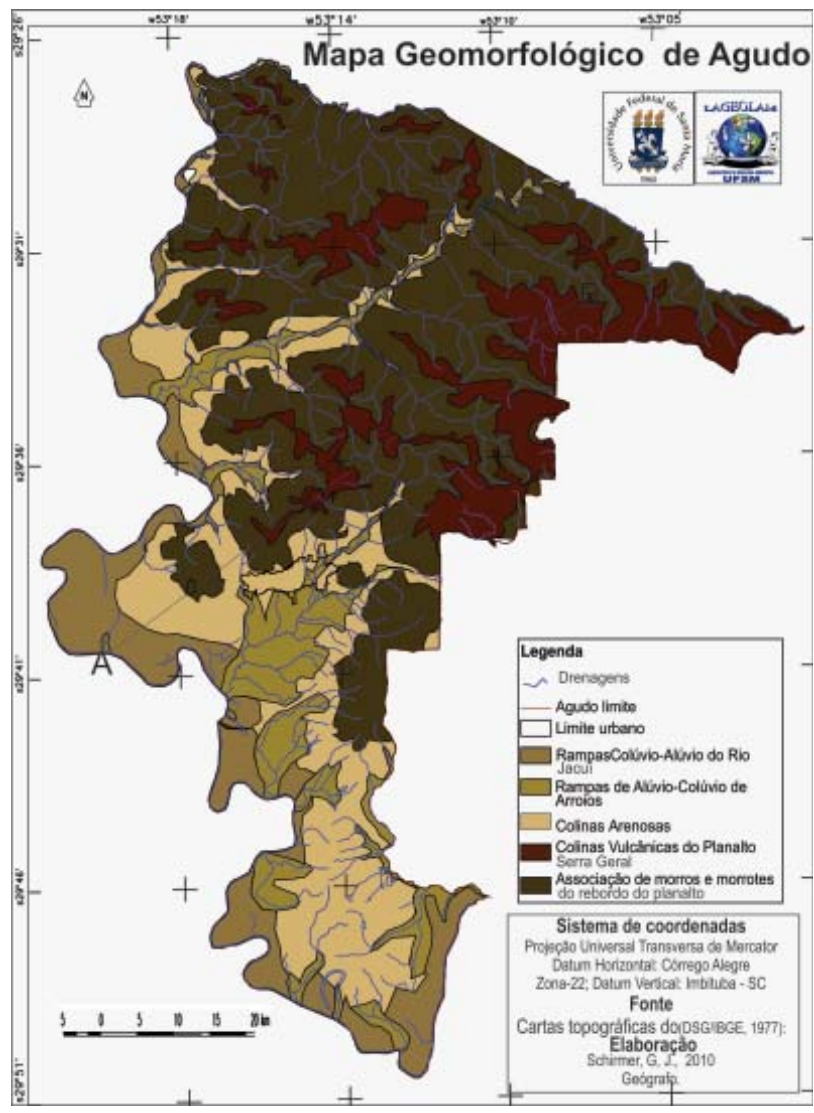

Figura 8 - Mapeamento Geomorfológico do municipio de Agudo.
A integração das informações sobre o substrato, o relevo, os materiais e processos superficiais permitiu definir seis unidades geomorfológicas no município de Agudo, como pode ser visualizado na figura 8 .

\section{Unidade de Rampas de Colúvio-Alúvio do Rio Jacuí}

No município de Agudo, o Rio Jacuí vem de áreas encaixadas do Rebordo do Planalto, porção noroeste do município, e na Depressão Periférica, em áreas de baixa declividade, começa a desenvolver um canal meandrante ao longo do curso (figura 9), com extensa planície de inundação.

Forma um relevo plano com declividades inferiores a $5 \%$ e altitudes inferiores a 70 metros. O modelado está associado aos depósitos recentes do rio que ocorrem sobre um substrato predominantemente de rochas sedimentares areníticas. Os solos são profundos, mal a imperfeitamente drenados.

O rio Jacuí apresenta um leito maior com seção transversal larga e o leito menor com margens baixas e fundo arenoso. Uma importante característica do leito menor do rio é o desenvolvimento de corredeiras, porções com acúmulo de blocos de rochas proveniente do Rebordo do Planalto (Miller, 1970). O uso do solo nessa área se dá predominantemente com o cultivo do Arroz, figura 10 .

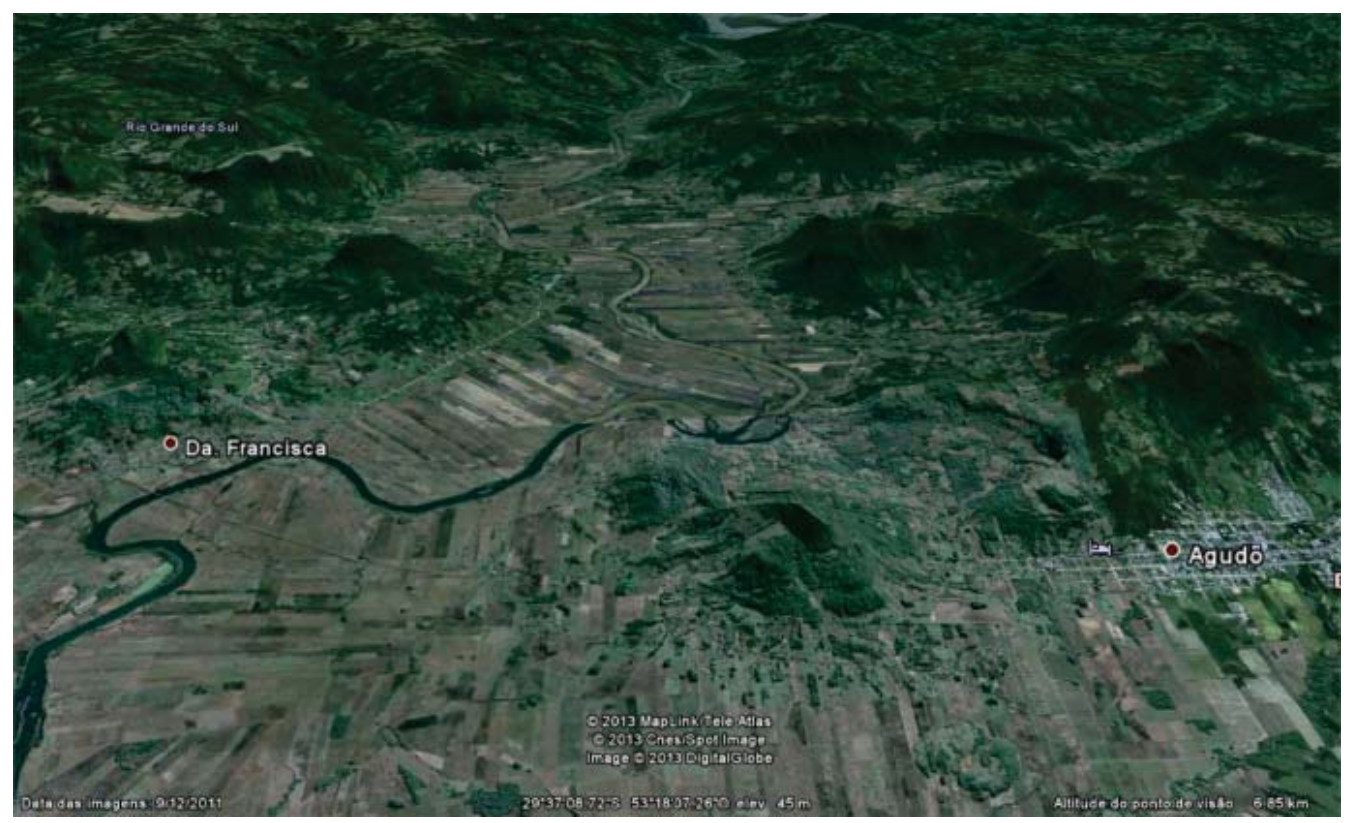

Figura 9 - Visada do canal do rio Jacuí com a imagem de satélite Ikonos. 

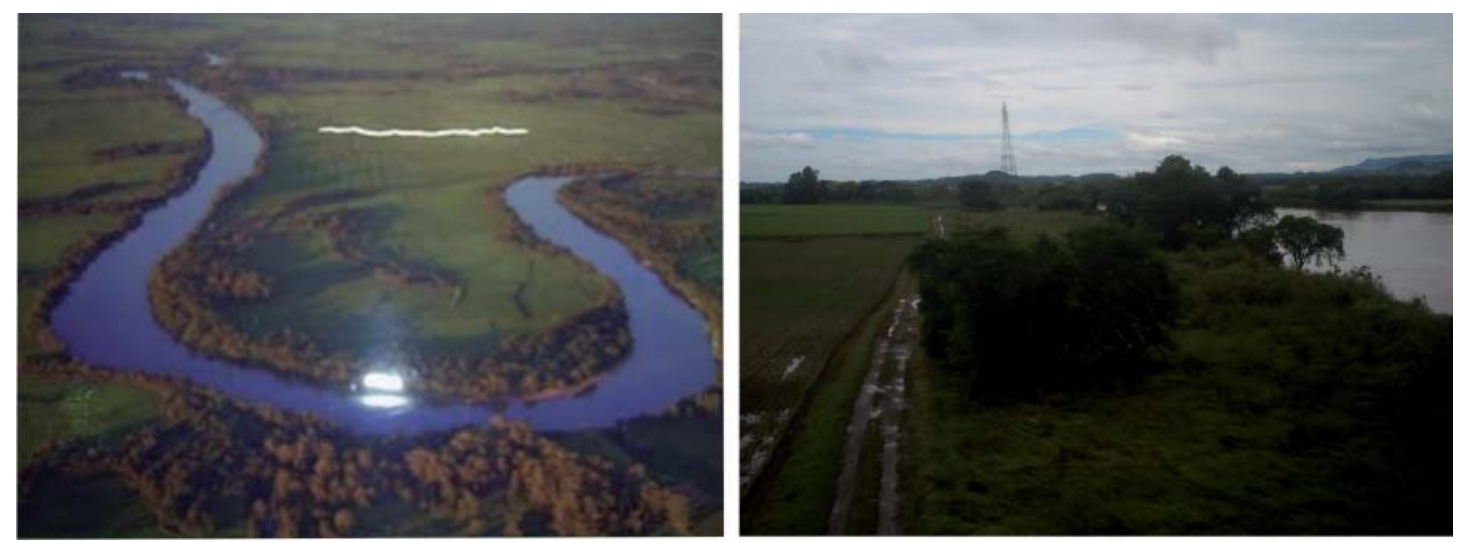

Figura 10 - Porção meandrante do Rio Jacui e o Cultivo do Arroz na sua planície.

Fonte: Ribeiro Filho. 2010.

\section{Unidade de Rampas de Alúvio-Colúvio dos Arroios}

Nesta unidade o relevo apresenta uma topografia plana, com o predomínio de rampas(áreas planas a suavemente onduladas) e declividades menores de 5\%, com altitudes inferiores a 180 metros. Esta unidade é composta por depósitos recentes formados por fragmentos originados de rochas vulcânicas e sedimentares, que através dos processos de dinâmica superficial acumularam-se nas áreas de fundo de vale, formando as planícies de acumulação dos arroios. Os solos são hidromórficos com baixa capacidade de drenagem, predominantemente do tipo Planossolos.
Esta unidade é formada pelas áreas planas dos vales, identificadas pelas áreas de acumulação dos arroios Hermes, Corupá, Lino, Krema, Prata, Várzea e Sthal. Estes modelados de baixas declividades, que correspondem às rampas de alúvio-colúvio dos arroios, são formados por feições superficiais compostas de sedimentos quaternários com variação textural. As principais atividades realizadas nesse local são o cultivo do arroz e do fumo (Figura 11).

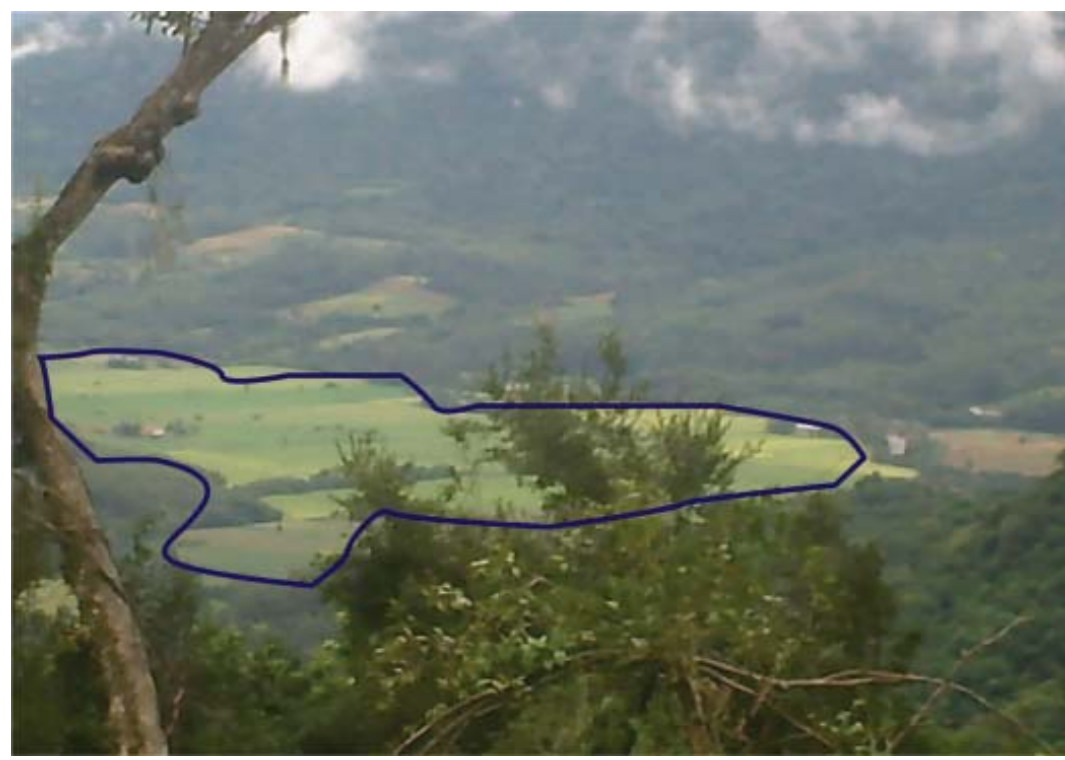

Figura 11 - Cultivo de arroz nas Rampas de Alúvio-Colúvio de Arroios, 2010. 


\section{Unidade de Colinas Arenosas}

Esta unidade é caracterizada por um relevo com vertentes de declividades menores que $15 \%$ e comprimentos ao redor de $1.000 \mathrm{~m}$ e amplitudes ao redor de $40 \mathrm{~m}$. As altitudes variam entre 90 e $200 \mathrm{~m}$, no norte do município. O substrato rochoso predominante nessas áreas são arenitos de origem fluvial, que quando friáveis são facilmente intemperizados e desgastados pela erosão, o que permite configurar um modelado de paisagens suaves, com vertentes convexas, arredondadas e de média altitude. Esta unidade apresenta solos do tipo Argissolos arenosos e profundos. O cultivo do fumo é a principal atividade realizada nesse local, figura 12 .

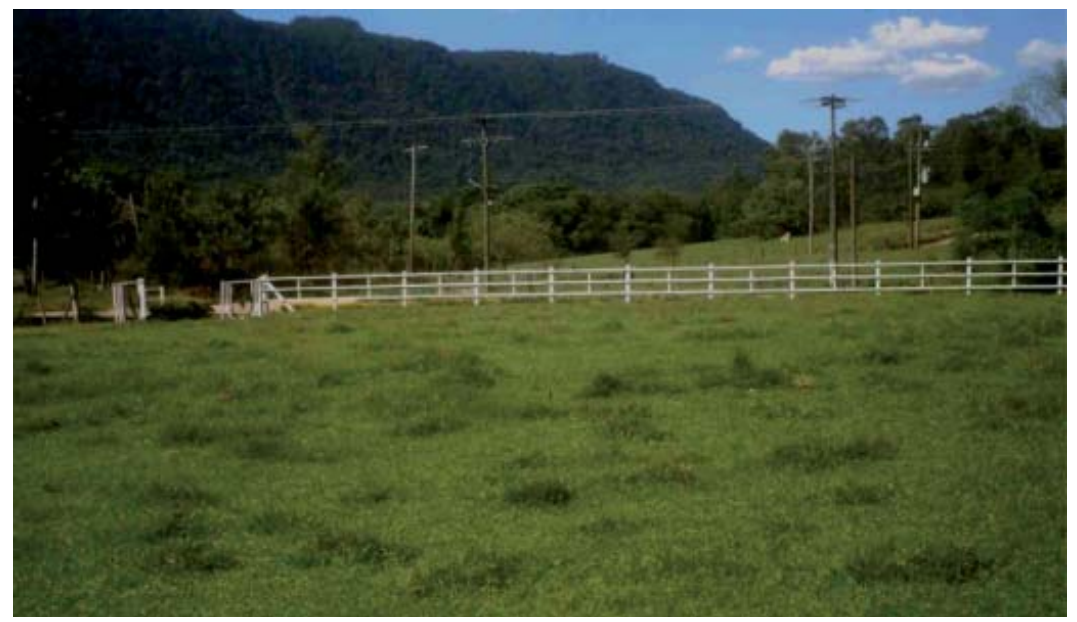

Figura 12 - Colina de arenito em Picada do Rio, 2010.

\section{Unidade de Colinas Vulcânicas do Planalto Serra Geral}

As colinas de rochas vulcânicas encontram-se em altitudes elevadas acima de 400 metros, em declividades predominantes menores que $15 \%$. O substrato faz parte do domínio morfoescultural do Planalto da Serra Geral, o qual apresenta sua origem ligada ao vulcanismo que cobriu os sedimentos da Bacia do Paraná no final do Mesozóico.

Os solos encontrados nesta unidade compreendem uma associação de Cambissolos e Argissolos, bem drenados, apresentando um perfil de alteração pouco a bem desenvolvido, figura 13.

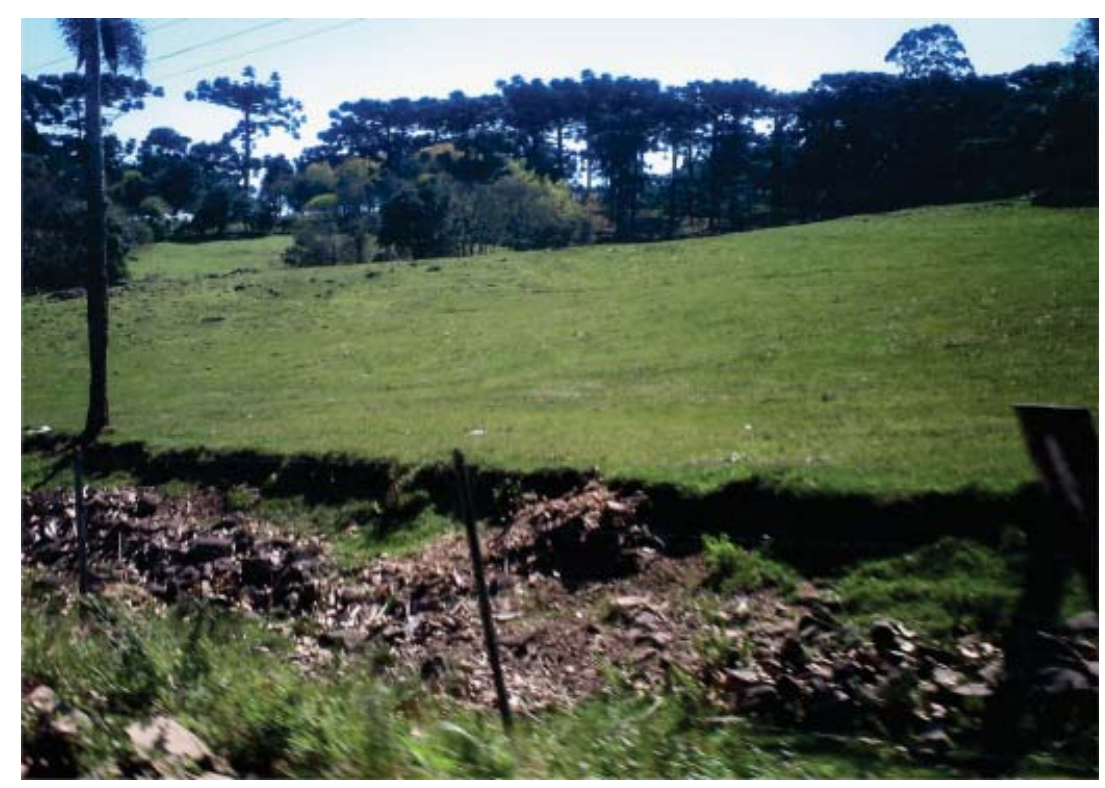

Figura 13 - Colinas Vulcânicas no Complexo da Serra, 2010. 
As colinas pertencentes a este modelado apresentam características de vertentes convexas de vales encaixados e topos planos. Os usos predominantes estão relacionados ao cultivo de fumo, milho e pecuária,

\section{Associação de Morros e Morrotes do Rebordo do Planalto}

$\mathrm{Na}$ unidade as formas de relevo predominantes são morros e morrotes de rochas vulcânicas, com algumas porções intercaladas de rochas de arenito eólico, demarcando contato de derrames, onde aparecem surgências, normalmente formando pequenos patamares entre-escarpas. A unidade ocupa altitudes entre 120 e 400 metros.

As vertentes entalhadas formam vales encaixados de encostas íngremes, com um grande número de cabeceiras de drenagem (cascatas), e declividades superiores a $15 \%$ que restringem o uso e ocupação, predominando a cobertura vegetal, figura 14 .
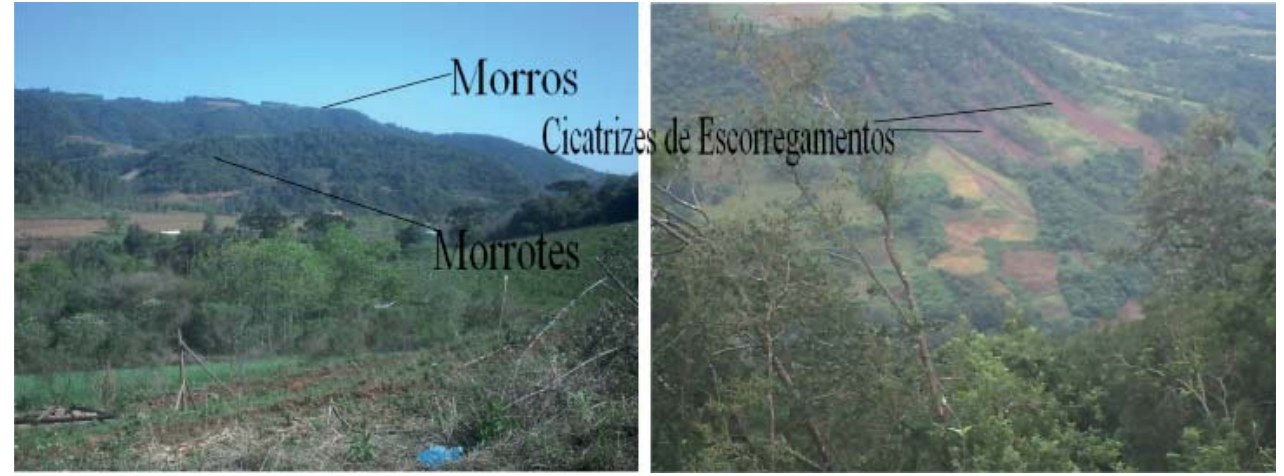

Figura 14 - Morros e morrotes mostrando cicatriz de escorregamentos. Observa-se, também, cultivo de fumo na encosta, 2010.

Aparecem ainda, escarpas abruptas associadas às sequências de derrames. A erosão, os deslocamentos de blocos e os escorregamentos são os processos de dinâmica superficial presentes nessas áreas. Os solos são de cor escura, predominam os Cambissolos e Neossolos, bem drenados. Com exceção tem-se os pequenos patamares entre-escarpas presentes nessas áreas, onde pode-se encontrar Argissolos.

\section{Considerações Finais}

A compartimentação de unidades geomorfológica do município de Agudo, com informações obtidas de escala com base 1:50000, trouxe uma caracterização da geomorfologia do município a partir da integração dos elementos naturais da área e dos processos a eles envolvidos.

Sendo assim, cada unidade definida se caracteriza por diferentes processos superficiais que podem condicionar o uso do solo. Dessa forma, acredita-se que o estudo geomorfológico, realizado de forma que integre os diversos elementos naturais da paisagem, serve como uma importante ferramenta de planejamento e gestão territorial.

\section{Referencias Bibliográficas}

DE NARDIN, Dionara; ROBAINA, L. E. S.. Zoneamento geoambiental do oeste do Rio Grande do Sul: um estudo em bacia hidrográfica em processo de arenização. Santa Maria, Artigo Sociedade \& Natureza, 2009.
DE BIASE, M. Carta de declividade de vertentes: confecções e utilização. Geomorfologia. São Paulo: Departamento de Geografia/FFLCH/USP. v. 21, p. 8-13, 1970.

INSTITUTO BRASILEIRO DE GEOGRAFIA E ESTATÍSTICA (IBGE). Diretoria de Serviços Geográfico. Porto Alegre: Primeira Diretoria de Levantamento, 1977.

IBGE. Instituto Brasileiro de Geografia e Estatística.

Projeto Radam Brasil: Geomorfologia (Folha SH-21. Santiago e Alegrete). Rio de Janeiro, 2003.

PENTEADO, M. M. O. Fundamentos de Geomorfologia. 3 ed. Rio de Janeiro: Fundação IBGE, 1985.

SCHERER, C. M. dos S., et al. Arcabouço Estratigráfico do Mesozóico da Bacia do Paraná. In: HOLZ, M.; DE ROS, L. F. O. Geologia do Rio Grande do Sul, 2002.444 p.

SCHIRMER, G.J., Mapeamento Geoambiental Municipal de Agudo-RS. Monografia Geografia_UFSM, Gerson Schirmer, 2010.

MENESES, P. R. Fundamentos de Sensoriamento Remoto. Universidade de Brasília. Brasília - DF: Departamento de Geociências. Brasília. Texto Universitário. 2004.

MÜLLER FILHO, I.L. Notas para o estudo da geomorfologia do Rio Grande do Sul, Brasil. Publicação Especial n.1, UFSM/ Departamento de Geociências, 1970.

WILDNER, W; RAMGRAG, G. E.; LOPES R. C.; IGLESIAS, C. M. F. Mapa Geológico do Estado do Rio Grande do Sul. Escala 1:750000. CPRM, Serviço Geológico do Brasil. Porto Alegre, RS. 2006.

ROSS, J. L. S. Geomorfologia. Ambiente e Planejamento. São Paulo: Contexto, 1990.

TRENTIN, Romário. Mapeamentogeomorfológico e caracterização geoambiental da Bacia Hidrográfica do Rio Itu - Oeste do Rio Grande do Sul - Brasil / Romário Trentin. - Curitiba, 2011. 